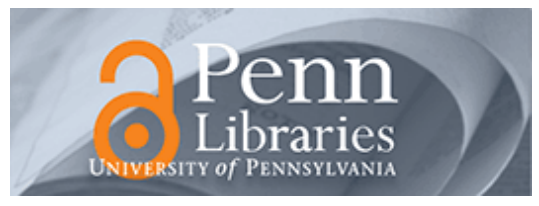

University of Pennsylvania

ScholarlyCommons

Management Papers

Wharton Faculty Research

3-2009

\title{
Innovation and Strategic Renewal in Mature Markets: A Study of the Tennis Racket Industry
}

Hann Earl Kim

Johannes M. Pennings

University of Pennsylvania

Follow this and additional works at: https://repository.upenn.edu/mgmt_papers

Part of the Advertising and Promotion Management Commons, and the Business Administration, Management, and Operations Commons

Recommended Citation

Kim, H., \& Pennings, J. M. (2009). Innovation and Strategic Renewal in Mature Markets: A Study of the Tennis Racket Industry. Organization Science, 20 (2), 368-383. http://dx.doi.org/10.1287/orsc.1080.0420

This paper is posted at ScholarlyCommons. https://repository.upenn.edu/mgmt_papers/127

For more information, please contact repository@pobox.upenn.edu. 


\title{
Innovation and Strategic Renewal in Mature Markets: A Study of the Tennis Racket Industry
}

\begin{abstract}
This paper presents a study of successive new product introductions in the mature tennis racket industry. The inquiry examines novel design's important role in strategic renewal, under the assumption that innovation includes not only the development, production, and launch of new products, but also communication between firms and market. We explore this industry's transformation through the strategic actions of innovative firms and subsequent competitive contagion. A tennis racket innovation triggers competitors' imitative reactions and sways the market toward a new de facto standard when the new product launch includes marketing such as product endorsement by high-profile professional players and advertising. Our results indicate that innovators should actively manage various industry participants as an integral part of their strategic renewal efforts, especially when facing rivalry with "me-too" peers. We suggest the interface between firms and consumers as a next focus for research on strategic renewal.
\end{abstract}

\section{Keywords}

innovation, endorsement, advertising, new product design, industry evolution, tennis racket

\section{Disciplines}

Advertising and Promotion Management | Business Administration, Management, and Operations 


\section{TECHNOLOGICAL EVOLUTION: LEARNING AT THE FIRM-CONSUMER INTERFACE}

\author{
Johannes M. PENNINGS \\ Department of Management \\ Wharton School \\ Locust Walk Suite 2000 Steinberg \\ Hall-Dietrich Hall \\ Phone +1 2158987755 \\ Pennings@wharton.upenn.edu \\ and
}

Faculty of Business and Economics

Tilburg University

10 Tjalling Koopmans Building

Tilburg, Netherlands
Hann Obl KIM

\author{
KDI School of \\ Public Policy and Management \\ Seoul, South Korea \\ $+82-31-514-6668$ \\ hann_kim@hotmail.com
}

The authors thank Paul Allison for extensive assistance in the analysis of the data. We appreciate the generosity of Sports Research Inc, Princeton NJ in making their data files accessible. We also appreciate the comments of Rajshree Agarwal, Eric Bradlow, Christophe van den Bulte, David Hsu, Sarah Kaplan, Will Mitchell, Sonali Shah, and Peter Roberts and two reviewers.

RevisedApril 14, 2007 


\title{
Technological Evolution: Learning at the Firm-Consumer Interface
}

\begin{abstract}
Invoking a learning perspective, this paper examines the technological evolution in the tennis racket industry. We examine the interface between firms and their consumers. Through endorsements by star players, as 'lead-users,' as well as through advertising, firms support their strategic renewal efforts as indicated by new product introductions, create a tipping point and tilt the market in their favor. The empirical results on endorsements and advertising show that manufacturers of new sport equipment involve consumers in a process of joint-learning that fosters the spread of discontinuous innovations-i.e., new model introductions. Endorsements are critical when the product is novel, but when they age advertising takes their place in sustaining diffusion of innovation. We conclude that innovators can and should condition the selection environment in their favor because uncertainty and ambiguity involving radical innovations open up the window of opportunity to do so. The findings are also suggestive for issues of strategic renewal.
\end{abstract}

Keywords: technological evolution, learning, endorsement, advertising, tennis racket 


\section{Technological Evolution: Learning at the Firm-Consumer Interface}

\section{Introduction}

Technological evolution has been an important subject since Schumpeter's pioneering work on innovation. Markets evolve and undermine the status quo whenever new technologies displace old ones. Whether firms initiate or amplify a gale of creative destruction, they exhibit some capacity at strategic renewal—for example endowment of dynamic capabilities and open innovation. Open innovation provides market intelligence, organizational learning and the ability to absorb extramural knowledge, thus conferring greater control over the outcomes of efforts in repositioning themselves in the market place. Customers who become integrated into the product development process also engage in learning and shape the product attributes to render them more congruent with their needs. In this study we delve into the firm-consumer interface and explore how firms might achieve integration of the consumer into strategic renewal efforts through their cooptation, together with other marketing efforts such as advertising. We view such actions involving firms and their clients as collective or market level learning, encompassing both adaptation to the initial stage of product launching and subsequent spread into the wider market environment.

In this paper we attempt to further elaborate on these issues by integrating industry, firm, product and individual levels of analysis, thus documenting the role of human agency in shaping product innovation and its diffusion over time, while also revealing the interplay between industry and firm level phenomena. This paper is positioned in the domain of organization science but draws from insights in marketing science, behavioral economics, organizational sociology and the management of technology. We examine a range of product innovations in the tennis racket industry leveraging multi-level information where the interplay between firms and their customers evolves over time. 
The learning process opens up an opportunity for the innovator to shape consumer experience with radical innovations and their preference formation through promotional activities designed to enhance consumer appreciation of innovations. The change in attitude might emit strong signals to competitors about the market acceptance of an innovation. Rivals replicate the innovation even at the cost of royalties and cross-licensing and the whole industry tips to a new equilibrium.

The context of empirical investigation is the tennis racket industry. While the simple appearance of the tennis racket may lead us to think that there is not enough room for innovative action, the industry has actually experienced a controversial innovation race since the mid 1970s. A close examination of the history of racket development reveals also numerous ex post failed innovations that were technically solid. This allows us to examine the factors contributing to the success and failure of radical innovations while avoiding so-called survivor bias which is common in innovation and strategic renewal studies. The analysis deals with the launching of models fitting a novel product design architecture and suggests that professional endorsement signals the technical feasibility and market existence to both consumers and firms. A wave of new model debuts reveals the effects of endorsements over advertising that marketing science deems indicative for diffusion of innovation (compare Chandy, Tellis, MacInnis, and Thaivanich 2001; Ganesh and Kumar 1996). The frequency of replication by competitors significantly increases when the innovator secures the endorsement of top professional players.

The remainder of this paper is organized as follows. We first examine existing approaches to the acceptance of discontinuous innovations in the market and explore technological change as a learning process on both sides of the market: consumers and firms. Next, we describe the empirical setting for the analysis: the technological change in the tennis racket industry. A brief history of the racket development is presented and the controversy regarding successive discontinuous innovations is documented. The main idea of the paper - the innovator's active involvement in shaping consumer preferences through promotional activities 
and the consumers' empowerment in affecting a firm's new product development activities - is tested in the tennis racket industry. We conclude by discussing the results and the contribution of the study to the literature on technological change and strategic renewal.

\section{Theoretical Development}

\section{1. Literature Review}

One of the critical concerns in the literature on evolutionary change of market and technology has been the emergence of successful or dominant innovations and their subsequent influence on the competitive dynamics of the industry. In particular, the mechanism through which uncertainty and controversy regarding radical innovations, their technical merits and potential for further development get resolved in the market has occupied a central position. Previous studies can be classified into two broad categories depending on their relative emphasis towards supply versus demand side of market exchanges.

The first stream of research focuses on the supply side. For example, Van de Ven and Garud (1994) documented decisions made by the National Institutes of Health and the Food and Drug Administration significantly conditioned the direction of technological development around the multi-channel over single-channel cochlear implant device even though technical uncertainty regarding the two competing technologies largely remained unsolved. In a study of the machine tool industry, Noble (1984) described a coalition between MIT and the U.S. Air Force as a critical factor for the prominence of the numerical control machine tool over its competitor, the recordplayback substitute. Cusumano, Mylonadis, and Rosenbloom (1992) investigated the role of strategic alliances among companies such as producers and movie studios for supporting the VHS format that legitimized it as a dominant design while marginalizing rival designs such as SONY's Betamax. Tushman and his colleagues reviewed the sociopolitical process of compromise and accommodation in the community of participants which accounts for the emergence of dominant designs (Anderson and Tushman 1990; Rosenkopf and Tushman 1998). These studies concluded 
unequivocally that the recursive relationships among suppliers and the regulatory authorities of the industry significantly influences the outcome of competition among alternative technologies.

The second group of studies examines the impact of demand side factors in the market acceptance of discontinuous innovations — what role do users perform in the legitimization of innovation, an issue commonly omitted from the literature on the rise and fall of dominant technologies and the associated cascading flows of technological progression? Von Hippel (1986) coined the term "lead user" to identify the key role of first-line consumers who are critical for the firms in successfully commercializing their innovations. Afuah and Bahram (1995) called our attention to the fact that the nature of an innovation might not be the same for everyone in the industry but the same innovation could have different implications for industry participants in various stages of the value chain. An innovation requiring incremental changes for suppliers could be an architectural innovation necessitating different knowledge and skill bases from the downstream companies. While an electronic sensor in the imaging sector might incrementally grow in capacity, its advancement can wreak havoc for ODMs dealing with shifts in digital camera architecture or for firms managing their component's interface with that of other component producers such as optical OEMs (Levine and Pennings 2007). Owners of complementary assets sometimes survive the competence-destroying innovations in the value network as its prevailing dominant design rests not solely on the core component but also on that of co-specialized assets as illustrated by font library owners that survived design shifts in typesetting equipment (Tripsas 1997). The literature on "direct" network effects shows that the adoption of an innovation critically depends on the number of its users because the rate of adoption increases in utility to the extent to which their number in the embedded market increases_-for example, the spread of email (David 1985; Arthur 1989; Katz and Shapiro 1985). "Indirect network" effects are observed when the utility of an innovation depends on the presence of companion products—-for example, imaging software. A technically superior product may not 
be adopted if a technically inferior counterpart has already built a large base of installment in the market through strategic maneuvering or due to “the historically small events” (Arthur 1989).

Also relevant to the process of technological evolution is the literature on innovation diffusion developed in various disciplines. In marketing science, Bass (1969) famously indicated that three aspects account for the specific shape of an S-curve. These include the total number of consumers eventually using the product, the level of external influence due to mass coverage, advertising and sales promotion and the degree of mimicry. It was this latter aspect that gained considerable currency in sociology and management, as indicated by the extended debate regarding the diffusion of tetracycline among physicians in four American cities due to cohesion or structural holes in adopters’ networks versus advertising (Burt 1987; Van den Bulte and Lilien 2001) and issues of legitimization of innovation as illustrated by the spread of new organizational forms (e.g., Davis 1991; Lee and Pennings 2002). The technical management literature explored issues of product performance and documented historical changes or "technological guideposts" over time (e.g., Sahal 1981). Since the diffusion of innovation research typically focuses on the detailed adoption process of a hugely successful innovation, it complements the above mentioned technology management literature that investigates the emergence of a winner among alternative technologies.

Recent scholarly developments taking both supply and demand side factors into consideration shed new insights on technological evolution. The disruptive technology framework by Christensen (1997) deals with demand side factors and often combined institutional, cognitive and technological adoption obstacles. Examining the process by which an arguably inferior technology finds its niche and often takes over the mainstream segment the incumbent firms occupied, Christensen (1997) highlights the importance of taking both the rate of technological improvement and what the mainstream market demands into consideration. When the existing technology provides the level of performance in excess of what the mainstream market can absorb, a new technology with attributes that are not attractive to the mainstream 
customers is likely to take a root in emerging niches. Adner (2002) later delineates the conditions in which a technology becomes disruptive by invoking the concept of preference overlap and symmetry. In the study of take-off phenomena of 30 innovations ranging from automobile to cellular telephone, Agarwal and Bayus (2002) explain that the timing of sales take-off is determined by the combination of outward shifting supply and demand curves. While the entry of new firms that puts downward pressure on price has traditionally been identified as a key driver of the take-off phenomenon, they illustrate that it is the demand shift caused by the firm entry through improvement in product quality and increased awareness and availability of products that ignites the sharp increase in sales.

This study is an attempt to complement the recent work incorporating supply and demand factors. The point of difference is that it proposes a new perspective on the market selection of discontinuous innovations by treating technological evolution as a process of learning by both producers and consumers. Prior research assumes that (potential) users have an established set of preferences for new products and, therefore, the major concern for the firm is the identification of unrevealed preferences and the requirement to satisfy them (Carpenter and Nakamoto 1989). However, we argue that the consumer experiences with discontinuous innovations ought to be likewise framed as a learning process in which consumers become familiar with the performance characteristics of the novel product. Consistent with the new insights regarding "open innovation” (e.g., Piller 2001; Chesbrough 2003), just as consumers form their preferences about the innovations, firms learn where their customers stand and adjust themselves accordingly. This evolutionary learning process on both sides of market exchanges produces discontinuities in strings of dominant technologies over time.

\section{2. Technological Evolution as a Learning Process}

Let's first look at the consumer side. Scholars in many disciplines argue that consumer experience with innovations should be viewed as a learning rather than a rational choice process, 
in which consumers choose the option maximizing their expected utility based on their given and fixed preferences. First, the literature in behavioral decision making and organization theory has argued that preferences are not just revealed, but constructed (Payne, Bettman, and Johnson 1992; Frenzen, Hirsch, and Zerrillo 1994). In a critique of the rational choice models, March (1978) pointed out that individual preferences should be treated as being constructed because they appear to be fuzzy, inconsistent and flexible. Therefore, the metaphors of development and construction are more appropriate than those of search and discovery (March 1988). The research by Kahneman and Tversky similarly showed how bounded rationality and acquired preferences condition their development over time, for example through the mechanism in which the initial starting point exerts a significant influence on later choices (e.g., Kahneman, Slovic, and Tversky 1982).

Second, economists also note the malleability of preferences and call for treating them accordingly. In their computer simulation, Aversi et al. (1999) indicated that preferences of boundedly rational consumers are endogenously determined and evolve over time through innovation and social imitation. Witt (2001) suggested that the theory of economic growth should pay attention to the demand side, including the rise of consumer preferences and their change over time. In contemporary societies, consumers face an unprecedented range of new products and services about which they have not developed clear preferences and consumption knowledge (Galbraith 1958). Therefore, the process by which consumers learn to consume new products and services should be at the center of the theory of economic change (Cowan, Cowan, and Swann 1997; Metcalfe 2001).

Third, marketing scholars have long investigated the preference formation process as a source of competitive advantage. In their pioneering research, Carpenter and Nakamoto (1989) showed that the firm engineering a new product category enjoys an enduring advantage because consumers begin to form preferences around its product attributes. While consumers did not yet exhibit well defined preferences about new product's attributes due to its novelty, they learn to 
value the attributes offered by the pioneering firm through trial and error and subsequently update their preferences. Other studies likewise have shown that the early experiences in a product category have long lasting effects through evolution of consumer preferences (Hoeffler and Ariely 1999; Heilman, Bowman, and Wright 2000; Ganesh and Kumar 1996).

In short, these studies across different disciplines argue that consumer preferences are not exogenously given or permanently fixed, but instead are constructed with the implication that innovating firms should reach out to potential consumers. Consumer preferences are endogenously determined, fluid and malleable, and shaped through experience-either through direct exposure or vicariously. This learning perspective is a particularly appropriate framework for the analysis of discontinuous innovations accompanying qualitative changes. Unlike incremental product enhancements, discontinuous innovations bring new features and attributes into the market and their consumers have to accumulate some familiarity. Being boundedly rational, they gradually acquire certain new and alternate preferences about new products and their architecture.

Learning also unfolds on the supply side. Incumbent and entrepreneurial manufacturers launch new products that potentially erode the position of existing ones and, as they succeed, accumulate improvements in process and product attributes (e.g., Wright 1936; Argote, Beckman and Epple 1990). A successful innovation is widely imitated when evidence grows about the presence of a technically superior solution and the market is willing to pay for it (Malerba 2006; Windrum and Birchenhall 1998). Market feedback from lead users, from their purchase and input to improve the performance, triggers a bandwagon and further drives the new product's legitimization toward a new dominant status. However, since technical aspects often provide conflicting information as to the relative success of innovations ex ante, the firms look for nontechnical sources of market feedback.

One class of literature investigated the firm's position in the network. For example, Podolny and Stuart (1995) indicated that an innovator's status conditions the probability of its 
innovation to become extended. Status derives from an innovator's connectivity in a network of firms and can be inferred from whether or not the exchange is initiated by the focal firm. These authors argued that the innovation's controversy is rarely resolved through the logic of technology, and, as a result, the identity of the innovators - in this case semiconductor manufacturers - conveys to peer firms a critical piece of information about the innovation's prospect for further development. Firm status or brand serves as a signal regarding quality, particularly when their product is novel and untested. Technologists have indicated that firms might imitate the innovator by gauging market feedback with reduced entry threshold since such feedback significantly reduces market uncertainty (Metcalfe 2001; Windrum and Birchenhall 1998). If we conceive of incumbents and their learning process as a form of institutionalization with a rational and mimetic phase, they become increasingly prone to mimic the conduct of innovators and their new product launches. In fact innovators trigger bandwagon pressures through institutional (DiMaggio and Powell 1983) and competitive isomorphism (Bothner 2003). As more firms adopt an innovation, sales volumes grow exponentially, partly through costs and hedonic price reductions (Stoneman and Ireland 1983; Klepper 1996) and additionally through improvement of product quality and availability of complementary products (Agarwal and Bayus 2002). For example, the iPod has engendered an ecosystem with a conglomerate of hardware and software products resulting in both direct and indirect network effects (Katz and Shapiro, 1985) with attendant market growth.

When learning occurs on both sides of the market, the innovative firms enjoy additional opportunities for industry-level learning (Carpenter, Glazer, and Nakamoto 2000). Whenever discontinuous innovations (i.e., radical regarding predecessors’ products and services) are introduced, a clear separation between the firm and the consumer dissolves and the engagement between them exceeds the limited interaction, which is typical during periods of incremental change. Tushman and Rosenkopf (1992) believed that the innovator's active management of non-technical factors becomes particularly important when alternative technological systems 
compete for a dominant position in the market. The distinction between the firm and its environment becomes even less sharp when radical innovations are involved (Amendola and Bruno 1990). Therefore, the environment should be considered being structured or cognitively shaped rather than exogenously given (Rosa et al. 1999).

The introduction of a discontinuous innovation opens up the window of opportunity for the innovator to make consumers construct their preferences toward the innovation and thus shape the competitive landscape in its favor. Discussing the constructive nature of preferences, Schumpeter highlighted the importance of active management of consumer preferences by stating that:

\begin{abstract}
"Yet innovations in the economic system do not as a rule take place in such a way that first new wants arise spontaneously in consumer and then the productive apparatus swings round through their pressure. We do not deny the presence of this nexus. It is, however, the producer who as a rule initiates economic change, and consumers are educated by him if necessary; they are, as it were, taught to want new things, or things which differ in some respect or other from those which they have been in the habit of using. Therefore, while it is permissible and even necessary to consider consumers' wants as an independent and indeed the fundamental force in a theory of the circular flow, we must take a different attitude as soon as we analyse change." (Schumpeter 1934: 65 , italics original)
\end{abstract}

One such venue available to the innovator is various marketing strategies. Galbraith (1958) famously asserted that the role of advertising becomes very important in the industrialized economy since the basic needs which inspired traditional economic thinking are already fulfilled. Again, Schumpeter noticed the role of marketing efforts in the success of entrepreneurial efforts:

"There is obviously no lack of realism in the proposition that the great majority of changes in commodities consumed has been forced by producers on consumers who, more often than not, have resisted the change and have had to be educated up by elaborate psychotechnics of advertising." (Schumpeter 1939: 73)

It is important to notice that such entrepreneurial action for molding consumer preferences is necessary because consumers often resist the change (Schumpeter 1934). Schumpeter's comments are prescient and have become common knowledge in today’s literature regarding open innovation in which the customer is an integral component of the new product development 
process (Franke and Shah 2003; Shah 2006; Piller 2001). Particularly, when innovations are pathbreaking or discontinuous, we often encounter a high level of engagement, but even if innovations have reached a more incremental phase, it has become common practice to integrate suppliers and consumers into the process as illustrated by P\&G's concept of "connect and create" (Huston and Sakkab 2006). Discontiuous innovations evoke consumer resistance: the early products embodying new technologies are often crude and primitive (Agarwal and Bayus 2002) as illustrated by the very first digital cameras with their high price and low resolution (Levine and Pennings 2007); early innovations tend to also score poorly on traditional performance metrics that consumers are familiar with (Christensen 1997); and they often require investment in learning new skills to fully take advantage of new products (Arthur 1989; David 1985). Creating a momentum in its early stage is critical because innovators often lack the resources to survive a long period of slow takeoff (Golder and Tellis 2004). Once the innovator successfully attracts the consumer attention and motivates them to experiment with the new product, it sends out the signal for technical feasibility and market existence for consumers and producers alike. A virtuous circle is likely to kick in so that the rival's replication of the innovation pushes the demand as well as the supply outward (Agarwal and Bayus 2002).

\section{3. Theory and Hypotheses}

The concept of open innovation invites the inquiry into an examination of the strategic renewal and management of the firm-customer interface: how and when do firms and some of their customers engage proactively in the adoption and diffusion of innovation. Behaviors that we might observe in the boundary spanning systems include networking, exhibition of adoption behavior, sales promotion and advertising. It is beyond the scope of this paper to review these and other media of firm-customer interactions. For example, advertising might range from mass media commercials to a firm constructing a blog through its website in which customers review product and non-product issues as, for example, P\&G has achieved with its diaper products 
(compare www.pampers.com). Embedded clusters of buyers and sellers are observable in a variety of ways, including virtual communities, on site focus groups, as well as social networks. Likewise, tennis racket manufacturers might forge webs of tennis pro groups across the US or EU and cultivate a gossip or grapevine network about its innovations, and aggressively make them available to tennis pros as opinion leaders to activate a word-to-mouth dissemination of knowledge.

In the present paper, we frame the spread of an innovative product in terms of mediation between firms and consumers, but the actual data we exploit do not lend themselves to such mediation. Consumer acceptance is not observed, only the extent to which firms target consumers with product launches, advertising and endorsements (see Exhibit A). In Exhibit A, innovation is presumed to affect the level of (unobserved) demand for the product, which in turn conditions the imitative responses of competitors. Three factors determine the effect of innovation on peer firms' imitation; the quality of the product, the amount of advertising, and the level of endorsement by top professional players. As Exhibit A suggests, these factors affect consumer acceptance, but we do not capture such effects. Nor do we examine endogenous feedback among producers and consumers, although it is plausible that sheer advertising or endorsement might enter into their competitive interactions.

\section{Insert Exhibit A about here}

Advertising and product-use display through endorsement are two avenues through which firms expose customers with information and knowledge about new products. Product knowledge exists in both tacit and explicit form, and might be transferred through articulation and socialization (Nonaka 1994). Advertisements embody the functional and symbolic articulation of product attributes, performance potential and their matching with customer needs. Endorsements represent product-customer behavior through which the market at large is socialized into the use of the product. They are largely symbolic and signal unobserved functional or aspirational value. 
Novel products, whose attributes are ill-understood and discontinuous with users' pre-existing playing routines, face a higher threshold than established products. Knowledge and skills surrounding them are still largely tacit. The argument echoes that of Chandy et al. (2001) regarding advertising and age of product, with customers typically shifting their motivation and ability as products become widely adopted. Their paper, unfortunately, deals only with advertising, not with what they call "word-to-mouth.” Absent word-to-mouth information, advertising might function as a surrogate for dissemination of tacit information, but the very medium of most advertising reduces them to packing knowledge explicitly and as articulated knowledge, they often fall short in conveying functional and symbolic value-particularly when they are disseminated for novel products, ill-known or even less understood by the consumer. Naturally, endorsements often overlap with advertising, and the endorsing individual occasionally appears in the advertising and becomes then an integral part of an advertising strategy. Yet, endorsements by players, particularly skilled and visible consumers with ostentatious adoption tendencies are particularly important for novel products whose customers are deficient in their knowledge. Endorsement also facilitates learning through product feedback to manufacturers who can upgrade and improve the product design architecture and thus achieve an even greater fit between product characteristics and consumer needs. Compared to advertising, endorsements are therefore comparatively more effective during the early stages of market evolution. Only when adoption becomes more common and the product more "mature” should we observe a tipping from tacit media, including word-to-mouth and other forms of "socialization," to more articulate or explicit messaging such as advertising and other forms of “articulation” (Nonaka 1994).

We therefore hypothesize that product endorsement has a positive effect on the magnitude of new product launches while advertising affects product positioning when the product no longer occupies a null segment (i.e., a segment with zero customers) but instead has become saturated and has moved beyond the initial stages of the S-curve. We can therefore also hypothesize that the interaction between endorsement and age of the product design is strong and 
negative, while that between age and advertising is positive; older products reside in markets where customers have accumulated product relevant knowledge, and in fact have reached the apex of their purchasing learning curve, and use of product has become habitual. In younger markets with a prevalence of tacit knowledge, endorsements are efficacious in bolstering consumer acceptance, while in mature markets advertising gains in saliency for retention and expansion of product acceptance. Both endorsement and advertising are critical instruments for strategic renewal, but while the former overcomes initial obstacles towards market acceptance, the latter contributes to consolidation and entrenchment. Endorsement fits better with innovation, while advertising is in line with imitation.

Finally, we should consider the possibility that any new product might become a market failure in that customers fail to respond ostensible to firm efforts to adopt their products. The innovation and strategic renewal literature is fraught with survival bias in that the literature tends to focus on successful innovations. Not-so-successful innovations are typically censored before they have a chance to become part of some data archive. Even in simple case studies such as that involving VHS and Betamax, the authors (Cusumano et al. 1992) did not include the "best" of three in their report on the standard contest between Victor and SONY, and which suffered an even shorter life span than Betamax, i.e., the Philips 2000 video standard. In our research setting, we likewise encounter new product designs that failed in becoming a dominant design. We hypothesize a positive effect of innovation quality and examine whether such effects are conditional upon endorsement and advertising. We would expect the interaction to be negative and positive, respectively.

\section{Empirical Setting: The Tennis Racket Industry}

\section{1. A Brief History of the Tennis Racket Evolution}


The tennis racket industry provides an interesting opportunity for studying technological evolution because it has been through a series of technological breakthroughs since the $1960 \mathrm{~s}^{1}$ One wave of innovations focuses on materials. Since the success of metal tennis rackets in the late 1960s, various materials such as fiberglass, graphite, boron, Kevlar, and titanium have been used in different parts of the tennis racket in order to achieve optimal playing characteristics. The search for new materials is still going on.

Another series of innovations concerns the design aspect of the tennis racket architecture. Among others, three innovations stand out (American Tennis Industry Federation 1991; Collins and Hollander 1994; Patterson, 1999). The first is the oversize design introduced in 1976. The surface area of its face is $110 \mathrm{in}^{2}$ (or $784 \mathrm{~cm}^{2}$ ), while the traditional racket has the face of only $70 \mathrm{in}^{2}$ (or $460 \mathrm{~cm}^{2}$ ). The second is the widebody design introduced in 1987. While the traditional racket is $19 \mathrm{~mm}$ thick across the frame, the thickness of the widebody racket varies across the frame and the thickest part in the middle of the frame measures $39 \mathrm{~mm}$. The latest innovation is the extra-long racket, which is commonly known as being introduced in the late 1990s. The length of the extra-long racket from top to bottom is in the range between 28 inches (or $68 \mathrm{~cm}$ ) and 32 inches (or $71 \mathrm{~cm}$ ), whereas the traditional racket is 27 inches long. ${ }^{2}$

While the industry is typically depicted as jumping from one major innovation to another in about every ten years, a closer look at the history reveals numerous innovative products that are not often noted or just briefly mentioned as a footnote in the history of racket technology development. For example, unique string patterns have been tried by several companies: the racket called TopSpin by Davis had the diagonal string pattern (not the traditional pattern of

\footnotetext{
${ }^{1}$ Dahlin and Behrens (2005) analyzed the tennis racket related patents to come up with measures of technological radicalness. Their research has produced a useful framework to identify potentially radical technology ex ante. As we are interested in the interface between the firm and the consumer in the market and the commercialization efforts of the innovator, we approached the issue of radicalness differently (explained in the method section). In our opinion, the two studies complement each other.

${ }^{2}$ From the year 2000, the maximum length of the racket that is allowed to be used in the professional circuit and organized amateur events is 29 inches.
} 
perpendicular and horizontal directions) in the racket face; the company called Mad Raq launched rackets with strings going in three (two diagonal and one perpendicular) rather than the traditional two (perpendicular and horizontal) directions. The Snauwaert company introduced a racket of which the head is attached to the racket throat at 43 degrees tilted in order to reduce the stress on the player's arm and wrist. A racket with two planes of strings was launched by the Blackburne company, which claimed its innovative racket to be stiffer and have an effective playing area in the racket face that is bigger than the conventional racket.

In this study, we focus on the innovation in the racket design. While the use of new materials in racket construction in itself is interesting, it is extremely difficult to accurately decompose the materials employed from secondary sources. Furthermore, the design aspect of the tennis racket innovation has produced a wide variety of new rackets and generated a high level of both enthusiasm and confusion in the market as racket manufacturers have heavily invested in the design architecture since the 1970s. The innovations in the racket design that are included in the empirical study are described in the following.

\section{2. Discontinuous Racket Design Innovations Considered}

We are interested in the process by which controversy and confusion around radical technologies get reduced and, as a result, either accepted or rejected by industry participants. The critical concern is the selection of discontinuous design innovations in an unbiased fashion. A commonly used method is to rely on a group of panels to choose radical design innovations. However, it could suffer from the following issues. On the one hand, if those who are knowledgeable about the tennis racket industry are employed, they would easily pick design innovations that are successful in hindsight such as the oversize racket. On the other hand, if casual tennis players who don't know much about the technology are consulted, it is possible that the hugely successful technologies like the oversize racket might not get selected as they have already achieved the taken-for-granted status. 
The key issue in this study is to avoid the survival bias and assess new racket designs from industry participants’ viewpoint as if they were figuring out the value of new designs and making purchasing decisions in real time (Rogers 1995). Therefore, in the analysis for the success and failure of potentially radical design innovations, we included new designs that were (claimed to be) considered as being very different. When new innovations have the potential to break away from the tradition, they are accompanied with positive words like "revolutionary," "breakthrough," and "radical” in product reviews and advertisement. At the same time, the unfamiliarity resulting from being different could attract negative comments such as "weird," "funny," "unusual," and "controversial." So we selected the new technologies when the positive and/or negative expression appeared in product reviews and advertisement in the two most popular magazines in the industry, Tennis and World Tennis.

For example, the Prince oversize racket, which is considered the most important innovation in the tennis racket history, was included in the sample because it was referred to as "a radical departure... weird at most” (Tennis, December 1975). Wilson’s Perimeter Weighting System and BioSports’ Gripper were selected as they were claimed to be “revolutionary” (World Tennis, May 1981 and October, 1985, respectively). In contrast, a typical advertising for rackets that are not chosen as a revolutionary design reads like:

“The SILVER ACE... combines $80 \%$ graphite with 20\% fiberglass. The result... a powerful yet forgiving frame. Flexible where it needs to be; stiff where it needs to be; light where it needs to be; and strong where it needs to be. All this at a great value.” (An advertising for Pro Kennex’s Silver Ace appeared in World Tennis in 1984)

It does not claim to be revolutionary or radical. Nor does it generate controversy about racket design and performance. The message it conveys focuses on incremental improvement in racket performance by combining existing technologies in a better way. Rackets with such descriptions were not included in the list of radical racket designs. 
From a total data set of over 2,400 rackets, ranging from the 1960s to the 1990s, we examined the 1,463 tennis rackets introduced to the U.S. market between 1976 and 1992. The window of observation was chosen as the design related innovations significantly increased after 1976 and one of the key variables in the study, the performance measure, is not available after 1991 because the magazine containing the information stopped publishing. The criterion for classifying potentially radical technologies was performed by two examiners who were in agreement for choosing the eight technologies in the sample (see Table 1 for their description). ${ }^{3}$

\section{Insert Table 1 about here}

\section{3. The Controversy around the Innovations}

The technology management literature often claims that it is relatively clear-cut to measure the performance of simple products because "straightforward measures such as price/performance ratio” are readily available (Tushman and Rosenkopf 1992). However, numerous studies in the history and sociology of technology illustrate that uncertainty and ambiguity about innovations abound even in the case of simple products (e.g., Pinch and Bijker 1987) thus making those claims highly untenable if not inappropriate. The tennis racket is a good example: a simple product with considerable confusion around product enhancements. Two pieces of anecdotal evidence are particularly illuminating. First, the benefits of the oversize innovation by Prince were misunderstood in its early days. In a review article two years after the racket’s introduction, a well-known industry expert wrote:

“After playing the Prince racket for a while, I must admit that I was a bit disappointed... Innovation in any sport is healthy, but I feel the Prince is more of a gimmick, not a true step

\footnotetext{
${ }^{3}$ Some of the technologies related to the above mentioned expressions were excluded from the study due to the lack of quality measures. For example, Blackburne introduced a racket with two planes of strings in 1997. The July/August 1997 issue of Tennis mentioned it as “radically different.” However, the racket quality data obtained from World Tennis are not available as it went out of business in 1993. Diagonal string patterns by Davis and Volkl, which was described as “unusual” (Tennis, April 1981), failed to make it in the sample. While Volkl's racket was reviewed by World Tennis, the playability was described in words, not published in numbers at the time. The numerical measure became available two years later.
} 
forward in high performance racket technology. It is best used by beginners or novices.” (Fiott, 1978: 66, italics added).

This is not merely an isolated case for negative responses to the Prince racket disregarding it as a gimmick and downplaying its benefit as a simple psychological advantage. The ambiguity involved both engineering and consumer concerns.

In 1979, Dr. Howard Brody published a paper titled "Physics of the Tennis Racket," in which he showed that oversize rackets have definitive advantages over traditional size rackets due to larger sweet spots (Brody, 1979). He also acknowledged that players require retraining to get the maximum performance from an oversize racket because its sweetest spot is located 5 to $6 \mathrm{~cm}$ closer to the handle compared with the traditional sized racket. Therefore, what Brody (1981) showed was that while an oversize racket had without a doubt certain performance benefits, its handling necessitates a change in the highly tacit skills of playing tennis that are attainable only through repetitive practice. In the absence of such implicit knowledge on oversize rackets, its skeptical users might not compromise their playing styles. Those styles are strongly anchored to legacy equipment and render its design rather sticky. The implication is that active tennis players are reluctant to appreciate the advantages of the oversize racket.

Another pertinent illustration regarding causal ambiguity of innovative rackets might be found in the extra long racket, which is longer than the traditional 27 inches from top to bottom. In 1996, the International Tennis Federation, the rule governing body in tennis, amended the rules on tennis equipment that the maximum length of the racket should be 29 inches rather than 32 inches, effective from 1997 for professional players and from 2000 for non-professional ones. Its motivation was the presumption that the game of tennis could be negatively affected by the faster and more powerful serves made possible with extra long rackets (Felcyn 1996) and, as a result, began to lose the game's popularity as a spectator sport. Brian Tobin, the president of the ITF said: 
“We don’t want all the tennis players at the club serving like Philippoussis [a top professional tennis player holding the fastest serve record at the time, i.e., late 1990s-early 2000s] with nobody being able to return the ball. We believe [we] are correct, but we're not able to prove [it] at this point, any more than the manufacturers, I suppose, can prove the use of longer racquets will be better [for the game].” (Quoted from Tennis, March 1997: 33, italics added).

Not impressed by such a hasty decision without any scientific evidence, the Tennis magazine conducted an experiment. They asked Philippoussis to serve with three rackets - a 27 inch wood racket, a 27 inch graphite racket, and a 29 1/4 inch graphite racket. The results showed only a slight change in the speed of serve: the average speed of serves increased from 122 miles per hour with a wood racket, to 124 miles per hour with a 27 inch graphite racket, to 126 miles per hour with a 29 1/4 inch graphite racket. In fact, Pete Sampras, the top ranked player in the world in the late 1990s, also delivered a 124 miles per hour serve with a wood racket in an exhibition match (Doherty 1997). Later, Brody (1997) showed that a return to wood rackets would have had hardly any effect on ball speed. Surprisingly, however, a dramatic improvement was found in another measure of performance - the accuracy of Philippoussis' serves fluctuated from $60 \%$ of the serves in with a wood racket, to $52 \%$ with a 27 inch graphite racket, to $80 \%$ with a 291/4 inch racket. This experiment suggested that the real advantage of extra long rackets was that especially shorter players could put more serves in due to the extra length enabling them to hit the ball at a higher point. Yet, it remains quite remarkable that the ITF made such an important decision, with profound repercussions on the technological trajectory, all this in the absence of a simple test like the one conducted by the Tennis magazine. These examples illustrate rather convincingly the role of a discontinuous innovation and their ambiguity regarding the possible benefits which face users when they consider the adoption of a product that differs significantly from that of a preceding generation. Producers face uncertainty as such perceived or actual performance ambiguity engenders difficulty in anticipating market responses to a product launch. 


\section{4. Factors Determining the Acceptance of the Innovations}

Amid such confusion, the innovators have to look for ways to get their innovative rackets legitimized. As implied in the above section, a good deal of causal ambiguity surrounds the technical superiority of a racket design (the issue of technical quality will be discussed in detail in the next section). Unlike products tightly embedded in networks such as mobile telephony or email, network effects seem not to threaten the fate of racket innovations because its choice resides within the purview of an (atomistic) player. The purchase decision is neither embedded nor constrained by rackets manufactured, nor affected by her playing partners as long as the racket design remains within the parameter set by the ITF. Dominant coalitions of industry participants seeking to impose or negotiate a standard are absent; there is little evidence that racket manufacturers share critical knowledge or conspire otherwise. The rule governing body, the ITF, does not pick a particular innovation as the industry standard either. Rather, it only sets the boundary for the design parameters and levels the playing field for incumbents and potential entrants. Under these circumstances, the effort by the innovator to shape consumer preference toward its innovation seems critical not only in terms of the innovation's success in the market but also in relation to its evolution, nor do they face coercive isomorphism as is common in sports like soccer and baseball where equipment is tightly regulated. It is particularly important in the context of tennis because the field stresses the importance of preserving the tradition, which is challenged by technical developments in equipment. Furthermore, the sport of tennis, if not sports in general, puts a premium in developing physical proficiency and dexterity and competing on the basis of personal skills such that the reliance on cutting-edge equipment is deemed a sign of weakness if not dishonesty. Compare the anecdotal controversy involving Dutch speed skaters who were accused of rendering the playing field un-leveled through the use of NASA pioneered garment weaves, called “riblets,” reducing putative drag for speeding athletes (Baum 1998).

Altogether, such attributes increase the level of resistance to any performance enhancing 
innovation, and surmounting such resistance is even more important for the innovator of new equipment.

As discussed in the previous section, various marketing efforts by the innovator are deemed critical in the process of preference formation. One of the media through which an innovator influences consumer attitudes is advertising (Schumpeter 1934; Galbraith 1958; Van den Bulte and Lilien 2001; McKelvey 1998). Unless they are "lead users” (von Hippel 1986), consumers often try a demo of tennis rackets before making the purchasing decision. However, such an effort can be manipulated by the innovator due to ambiguity regarding racket performance. The consumer experience with a demo is likely to give an opportunity for the consumer to believe what they wanted because the experience is seen as objective and leaves a strong impression (Hoch 2002). Through advertising and media coverage, consumers form a tentative hypothesis or a "top-down” belief about racket quality before their learning by doing generates a "bottom-up” cognition (Gavetti and Levinthal 2000).

Experimental evidence in behavioral decision-making shows that when the consumers’ experience entails only ambiguous signals about product quality - as in the case of tennis rackets - they tend to interpret the experience as confirming their tentative hypothesis (Hoch and Ha 1986; Ha and Hoch 1989; Kempf and Smith 1998). Advertising is a medium through which the innovator might shape their preferences towards its products. Alternatively, manufacturers may alleviate causal ambiguity regarding a novel product design and strongly condition consumer choices by sending a strong message conveyed through endorsement of professional tennis players. The legitimacy of a new product is enhanced by having top players use the product because they are highly visible and respected in the tennis community. Furthermore, the causal ambiguity regarding the innovative product's performance will be significantly reduced when high status athletes play well with the racket. When the Prince oversize was first introduced, it was criticized by industry experts as a gimmick (Fiott 1978). However, negative responses soon disappeared when Pam Shriver, a female professional player, surprised the tennis world by 
advancing to the final of the U.S. Open in 1978 playing with that Prince oversize racket. Her achievement sent a strong message since she had never reached even the quarterfinals of women’s singles championship in any Grand Slam event before. This incident served as pseudo proof that the Prince racket was not just for beginners or novices needing extra help from the equipment but rather it could enhance the performance level for players at any level (Le Marche, 1986).

It is widely recognized in the marketing literature that using celebrities as spokespeople of the product increases its credibility. Three factors make celebrities as a credible source of information: expertise, trustworthiness and attractiveness (Ohanian 1991; Kahle and Homer 1985). Expertise brings a person's opinion more respect because her training and experience is believed to provide her with superior knowledge. Trustworthiness denotes the degree to which a person tries to offer objective information and be honest. Attractiveness predicts that a physically attractive person communicates information more successfully than a less attractive one. While earlier studies make no distinction among the three dimensions, Ohanian (1991) illustrates that they are mutually independent constructs and the effectiveness of a spokesperson depends on the match between her strength on the three dimensions and the product characteristics. In the tennis racket case, expertise is expected to carry more weight than the other two and professional players are an optimal vehicle for conveying the message. In fact, one of the examples that Ohanian (1991) used in her study is John McEnroe, who won seven Grand Slam championships in the early 1980s. While he receives very low scores on attractiveness and trustworthiness, he is rated as being very knowledgeable about sporting equipment. Her study shows that a spokesperson's perceived expertise with the product significantly increases the intention to purchase it. Firms recruit and pay top professional players to use their racket (Meadow, 1983). While some racket manufacturers aggressively approach professional players and persuade them to play with their rackets, others are reluctant to do so. Conversely, some professional players voluntarily use certain rackets without the firm's initiation because they have already played with 
the racket for a while. Even in this case, those players might insist on compensation for using the racket when they become a high-ranked player and produce good results in major tournaments. For example, Conchita Martinez, a top 10 female player from Spain, won Wimbledon in 1994 with an unendorsed Donnay racket. However, since the company refused to meet her demands, she switched to a Wilson racket. In fact, the racket that professional players use is very likely different from the very same brand racket available in the market because racket manufacturers adjust playing characteristics of the racket to their need. In an extreme case, professional players add cosmetics to make the racket look like the one they are supposed to play with. One professional player in the early 1970s painted his metal racket black because he wanted to make the racket appear as a graphite, not metal, racket. While he sought to revert to his original metal equipment, he couldn't do so because he was already compensated by the firm producing the graphite racket. The endorsement effect is most apparent when the product is endowed with a new technology. Since professional players’ endorsement provides familiarity, the innovator's decision regarding endorsement significantly affects the acceptance of the technology (Veryzer 1998). Again, the Prince oversize racket required consumers to abandon their concept of the tennis racket because the traditional size of 70 square inches was an inseparable element in defining what a tennis racket had been for a long time. This barrier to acceptance was successfully removed by the phenomenal achievement of Pam Shriver in the 1978 U.S. Open. With an event like this, consumers form a hypothesis and consciously seek for evidence supporting this hypothesis (Hoch and Ha 1986). The following quote from an industry expert accords with the above argument:

“...but if the past is any guide, successful racket design concepts will emerge from the ranks of tennis players and enthusiasts. "Familiarity seems to lead to conformity in this business," Leonard said.” (Ashley, 1993: 55).

Once the sales of a new product increase significantly following an endorsement, competitors are expected to introduce their own versions of rackets that are equipped with the 
same or similar technology, even at the expense of paying royalty for the patent. Firms focus their resources on the area where positive feedback is likely. Since the response to an innovation is not clear to racket manufacturers, they hold their move into new areas until they are convinced about positive feedback. Therefore, we expect to see the increased occurrences of the racket design replication with the professional player's endorsement of the innovation.

\section{Data and Analysis}

\section{1. Source}

A major portion of the data was collected from popular magazines, Tennis and World Tennis, the two most widely subscribed magazines in the business. As they carried the most upto-dated information on the events occurring in the tennis industry, the content analysis of the two magazines allowed us to identify newly introduced tennis rackets and their unique features. Both magazines ran sections reporting the latest development and reviewing new equipments. In particular, they regularly featured sections called "racket survey” in World Tennis and "racket review” in Tennis that provided detailed information of the rackets as a way to help their readers make informed choices on purchasing new rackets. The advertising section by racket manufacturers contained useful information as well. As racket manufacturers attempted to persuade consumers to purchase their newly introduced rackets, they often provided various description and highlighted unique features of their products. Through analyzing racket review sections and advertisement, we were able to identify the timing of new racket introduction and the unique features of the racket.

A preliminary survey identified over 2,400 rackets introduced during the period between 1953 and 1998. We decided to focus on the rackets launched between 1976 and 1993 for two reasons. First, while there were a few racket design innovations prior to 1976, it was the Prince oversize racket of 1976 that sparked the race for better tennis racket designs. Since this research focuses on innovations in racket design rather than materials, the rackets introduced before 1976 
were excluded. Second, one of the key variables of the study is the quality of the tennis racket incorporating various innovations (detailed description of the variable is provided in the next section). While the key quality measure published by World Tennis, "playability,” was published from 1983 to 1991, it contained the racket design innovations that were introduced before 1983 and covered the innovations from 1980. Therefore, the total of 1,244 tennis rackets introduced between 1980 and 1992 (as the dependent variable was lagged by one year) was examined for their unique features and design innovations incorporated.

We also collected data for other variables in the study such as the characteristics of the companies and the number of firms in the industry from the various issues of The Sporting Goods Directory published by the Sporting Goods Dealers Association. The size of the U.S. tennis playing population was collected from the sporting goods market research database compiled by Sports Business Research Network in Princeton, NJ.

\section{2. Variables}

The dependent variable is the number of new rackets with a particular design innovation that are introduced by competitors of the innovating company: for example, when the number of new oversized rackets was counted for 1985, those introduced by Prince, the innovator in this case, were excluded. The innovating firm often attempts to flood the market with different versions of the racket with its own innovative racket designs in order to serve the needs of different market segments as well as to create an impression that the innovation is popular and initiate a takeoff. Therefore, the essence of a racket design's success can be examined by teasing out replication by the innovating firm. We want to ascertain the propensity of producers to launch a product that is endowed with such "extrabrand” identity (compare Boyd and Mason, 1999).

For the quality of a racket design innovation, we used the data on racket performance collected from a series of racket reviews published in World Tennis. The magazine published a 
series of articles on racket quality based on extensive tests. One of the measures appeared in the magazine was called "playability," which was based on the judgment by test panelists who played with a racket at least an hour and provided a single score ranging from one to ten to indicate the intrinsic quality of a racket. ${ }^{4}$ The playability score from 1983 to 1991 reveals intriguing phenomena where the racket with innovative designs that are ex post identified as failure received fairly high scores in the playability test when they were launched. For example, the ergonomic design of Snauwaert was awarded the highest playability score in 1984 and the rackets made by Mad Raq with three-way strings also received very high marks. The extra long rackets, which are widely recognized as having been introduced in 1996 but have more than ten predecessors in the previous decade, received fairly good scores when they were introduced to the market: an extra long racket launched by MatchMate recorded the highest score in 1984, the same score as Snauwaert’s Ergonom, an ergonomically designed racket.

\section{Insert Figure 2 about here}

As we needed to capture the intrinsic quality of an innovation that is employed in many rackets, we chose to employ the highest playability score among the rackets embodying the same innovation as the value reflecting the true quality the innovation could achieve so far. For instance, the above mentioned extra long racket by MatchMate received eight in the playability, the highest score among all the rackets introduced in 1984, while Yonex’s extra long racket was given seven in 1985 and the one by Sentra was rated five in 1986. Although the extra rackets in

\footnotetext{
${ }^{4}$ The other set of measures was a lab test, which was measuring the performance of a racket along the three dimensions that are believed to critically determine its quality: stiffness, stability, and power zone. These were measured in a lab by scientific instruments. While these dimensions are considered to reflect the quality of a racket (Collins and Hollander, 1994), none of them in itself could represent a racket quality. We have attempted to come up with a single number based on the lab measures by regression and factor analysis. However, the constructed numbers exhibited a low level of correlation, about 0.2 , with the playability number. Therefore, we chose to rely only on the playability measure, which is closest to assessment by the tennis playing public.
} 
the later years received lower playability scores, we used the higher score achieved by MatchMate as the quality frontier for all extra long rackets in 1985 and 1986 because the MatchMate racket had shown that it is possible for extra long rackets to obtain such a level of quality.

Two additional product related characteristics were measured: advertising and endorsement by top professional players. As a proxy for advertising, we counted the number of advertising pages in Tennis, one of the most popular magazines in the industry. When a full onepage advertisement was dedicated to one tennis racket, we counted it as one. When multiple rackets appeared on a single page advertisement, we gave each racket the count of (1/the number of rackets on the page). Then we summed the number of advertising pages promoting a specific racket design. A radical technology appears not only in the innovator's advertising, but also in that of the the competitors as they promote their own brand of the racket incorporating a particular technology. For example, the oversize technology featured on the advertising by the competitors of Prince, the original innovator, because they attempt to attract consumers to their version of the technology. Since the advertising by competitors contributes to familiarity and acceptability of the technology as well, we constructed three advertising variables: one for the advertising by innovator, one for that by competitors, and a third one aggregating advertising for the whole industry.

Endorsement by lead users also involved a count. The number of top professional players employing a racket incorporating one of the eight discontinuous racket design innovations was constructed from various issues in popular tennis magazines such as Tennis and World Tennis and other publications on tennis. We defined top professional players as those who were included in the top ten players of the year list published by Association of Tennis Professionals (ATP) for male players and Women's Tennis Association (WTA) for female players, respectively, available from Collins and Hollander (1994). In addition to the top ten players both in men's and women's annual ranking, we also included those players who reached semi-finals at four Grand Slam 
tournaments, Wimbledon, U.S. Open, French Open and Australian Open, because they attracted a significant amount of attention from the tennis community and those matches were often televised on a national network, even though they were not top ten players. We considered such a classification of top ranked players as an objective measure of visibility and credibility as a source of information.

Finally, we include age, being the number of years since the first racket with the new racket design innovation entered into the market. We transformed this variable logarithmically.

Three variables descriptive of firms in this sector were included. We classified a firm (1) as an incumbent or a new entrant, (2) as either concentrated in tennis equipment exclusively or diversified into other lines of business, and (3) as an American company or a foreign firm. Finally, we included several market indicators such as the size of tennis playing population, the number of tennis racket manufacturers and the number of rackets available in the market.

\section{3. Count Data Analysis with Negative Binomial Regression}

Negative binomial regression was employed to analyze the data. It should be used to estimate count models when the Poisson estimation is not appropriate due to the problem of overdispersion (Allison, 1999). We used the GENMOD procedure in SAS. This methodology is particularly appropriate if we want to estimate a market's propensity to mimic products that share “extrabrand” attributes (compare Boyd and Mason, 1999). ,

The dependent variable for the regression was the number of new rackets embodying a particular racket design introduced by companies other than its innovator in one year. $\mathbf{X}_{1}, \mathbf{X}_{2}$, and $\mathbf{X}_{3}$ are vectors of variables, the description of which is included in Table 2. $\mathbf{X}_{1}$ denotes a vector of variables representing the environmental conditions at time $(t-1)$ : the number of tennis playing population, the number of tennis racket manufacturers and its square term, and the number of rackets in the market and its square term. All three variables are lagged by one year in 
order to capture their effects on the new tennis racket introduction in the following year. The second group of variables, $\mathrm{X}_{2}$, is a vector of the innovating firm's characteristics: binary variables on whether the innovator is (1) a new entrant or an incumbent, (2) a part of a multidivisional firm or a single line of tennis racket business, and (3) an American or a foreign company. The last vector in the equation, $\mathbf{X}_{3}$, represents variables capturing the characteristics of the product embodying a focal racket design: the age of the innovation, the quality of the racket incorporating a particular technology, advertisement pages for the innovation, and the number of top professional players using the racket with a particular racket design. These variables are centered to reduce the level of correlation between them and their interaction terms (Aiken and West 1991). They are also lagged by one year.

\section{Results}

Table 2 reports means, standard deviations and a correlation matrix for the variables in the models.

\section{Insert Table 2 about here}

The results of negative binomial regression on replication of discontinuous racket design innovation by competitors are reported in Table 3. Model 1 examines the effect of advertising on racket design replication by competitors. As hypothesized, advertising exerts a positive and significant influence on racket design replication by competitors. Following Van den Bulte and Lilien (2001), we have disaggregated the advertising variable into advertising by innovator and advertising by imitator. Model 2 indicates that the positive effect of advertising on new racket introduction with a particular racket design is mainly due to the advertising done by competitors rather than the innovator. This suggests that innovators rely on the means other than advertising to legitimize their innovative racket design. It also implies the herd behavior by imitators because 
the advertising of a particular racket design by imitators increases the number of new rackets with the design by competitors in the following period. The positive coefficient for professional endorsement in model 3 supports our hypothesis that the greater the number of top professional players who endorse a particular racket design, the more likely the racket design is adopted by competitors.

\section{Insert Table 3 about here}

To see whether the effect of the variables of our interest changes over time, we added the interaction terms between age of racket design innovation and two promotion variables, advertising and professional endorsement (models 4 and 5). In both models, the coefficients of the interaction between age of racket design innovation and innovation quality are positive and significant. It suggests that the effect of racket quality on the competitor's launch of new racket with a focal racket design increases as the racket design matures. This is consistent with our observation of the industry. When a new racket design innovation is introduced, the idea on which the design is based might have big potential. However, the first few rackets embodying the racket design often have failed to perfect the technology and need further improvement to make the rackets more playable. As more companies begin to work on the design, the quality of racket incorporating the design increases, and in turn attracts more competitors to launch new rackets with the design. The coefficient of professional endorsement still remains positive and significant (model 5), while the effect of advertising by imitators disappears with the interaction term (model 4).

In models 6, 7, and 8, both advertising and professional endorsement are included. While the high pairwise correlation between professional endorsement and advertising by imitator $(0.87$, $\mathrm{p}<0.001$ ) is a concern, it is not a sufficient evidence for the existence of multicollinearity. To check how serious the multicollinearity problem is when we have the two variables in the model, 
we have conducted diagnostic tests for multicollinearity. As PROC GENMOD procedure in SAS does not provide the popular diagnostic options such as tolerance and variance inflation factor (VIF), it is customary to assess multicollinearity with PROC REG as the issue of multicollinearity concerns the property of explanatory variables, not the dependent variable (Allison 1999). While there are no strict criteria for deciding the existence of multicollinearity, a widely used rule of thumb is the tolerance level less than 0.1 and the VIF level higher than 10.0 (Kleinbaum, Kupper, and Muller 1988). The test diagnostics indicated that advertising by imitator had the tolerance level of 0.30 and the VIF of 3.38, while professional endorsement had the 0.26 tolerance level and the VIF of 3.88. Therefore, despite their high correlation, advertising by imitator and professional endorsement do not seem to create a serious multicollinearity problem.

Model 6 has advertising by innovator, advertising by imitators, and professional endorsement. The effect of advertising by imitators, which is significant in model 2, disappears in model 6, while the coefficient of professional endorsement still stays positive and significant when advertising and professional endorsement are included (model 6). To examine the interaction between the variables of interest, we included the age interaction terms in model $\mathbf{7}$ and the interaction between advertising and professional endorsement in model 8. In both cases, the likelihood ratio test, twice the positive difference between the log-likelihoods (Allison 1999; Cameron and Trivedi 1998), indicates that the two models are better fits than model 6, which is only with main effect variables (13.72 (d.f. 4, p < 0.01) for model 7 and 23.08 (d.f. 6, p < 0.01 ) for model 8, respectively). When we introduce the interaction term with age of innovation (model 7), the effect of professional endorsement still remains significant and the interaction of age and quality turns out positive and significant, as in model 5. In model 8, the interaction between advertising and professional endorsement is introduced. Consistent with previous models, the main effect of professional endorsement and the age and quality interaction are positive and significant. Unlike other models, a few more interaction terms turn out to be significant. The age variable's interaction with advertising by innovator is positive, while its 
interaction with professional endorsement is negative. This suggests that as racket design matures, the effect of advertising by innovator increases while that of professional endorsement decreases. In other words, the legitimacy of a new racket design improves with professional endorsement in its earlier period and the influence of advertising by innovator on the introduction of new rackets with the design gets larger in the later period. The negative interaction between professional endorsement and the two advertising variables is consistent with the pattern exhibited by the age interaction with advertising and professional endorsement: the influence of advertising is bigger when the level of professional endorsement is relatively low. In short, a new racket design gets replicated by competitors when it is endorsed by top professionals in the early age and the advertising further increases the chance of replication in the later period.

Parenthetically, it should also be pointed out that some of the control variables are significant. The "density" or the number of competitors in the industry has a positive effect on the replication of innovation. The innovator is more likely to be a new entrant into this market of sport equipment, but is also more likely to be a diversified firm which is active in a number of other lines of business. The size of the market (i.e., the number of rackets and the size of the tennis playing population) has no effect on the innovation race being played out by those firms and its consumers.

\section{Discussion}

The results support our hypothesis that professional endorsement has positive effects on the probability of replication by competitors. When discontinuous innovations are introduced, their technical merits are not obvious at the outset. Then, industry participants, both consumers and competing firms, are inert and tend to stick to their present solutions that have served them well (Hoch 1984). The persistence of status quo is particularly strong in the tennis industry, where tradition is highly valued and reliance on novel equipment is discouraged. Under these circumstances, it is too naïve to expect innovative products to diffuse rapidly simply because they 
are endowed with better performing technology. Here, the active engagement by the innovator with the environment through the endorsement by top professional players sends a strong signal to the market that the uncertainty regarding market and technological quality has been properly managed. In other words, professional endorsement is one way to significantly increase consumer confidence about the novel products and to vicariously alleviate causal ambiguity about its performance. Its effect is shown to cascade into high levels of replication by competitors even at the cost of incurring significant licensing fees. Furthermore, combined with the decreasing effect of professional endorsement over time, innovation quality bears an important implication. Since most radical innovations in the tennis equipment industry receive mediocre scores on product evaluation due to the lack of familiarity, it is critical to increase the level of trust through lead users who represent credible role models.

This study suggests that the organizations increase their survival rates by changing the competitive landscape in their favor. Traditionally, research on organizational change has been divided into two camps (Levinthal 1992): the adaptation perspective (e.g., Cyert and March 1963) and the selection perspective (e.g., Hannan and Freeman 1977). Here it is put forward that the organizations can actively shape the selection environment by influencing the process of preference formation. The point was already advanced by Penrose (1952) in her discussion of the difference between biological and economic selection:

“... there is no a priori justification for assuming that firms, in their struggle for profits, will not attempt as much consciously to adapt the environment to their own purposes as to adapt themselves to the environment." (Penrose 1952: 813-814, italics added).

While she did not elaborate how firms can do so, our study suggests one venue: firms actively mold consumer preferences through promotional measures such as advertising and product endorsement. $^{5}$

\footnotetext{
${ }^{5}$ Recently, Lewontin (2000) made the same point in the context of biological evolution. Darwin's theory of adaptive evolution by natural selection assumes the clear demarcation between the organism and the
} 
In terms of research design, this study examined the ex post failed innovations as well as the successful ones. Previous studies on technological innovation have mostly focused on successful (in many cases, enormously successful) innovations. Therefore, technological evolution is deemed to consist of successful innovations, as if a 'rugged landscape,' jumping from one major platform or technology peak to another. While our understanding on technological evolution has thus been significantly improved, our grasp of not-so-successful innovations is still beyond our reach. At least two reasons dictate such an extension of our inquiry. First, we can obtain a more realistic picture of technological innovation. Only a tiny fraction of new ideas find their way into products, of which only a small percentage become successful. Attention to less successful innovations helps us realize that technological innovation is a very complex process in which not only technical factors but also economic, social and political ones play important roles. More importantly, not-so-successful innovations can be considered as a control group providing an opportunity to test the validity of claims solely based on success stories, and to circumvent the so-called survival bias that characterizes much of the literature to date. Therefore, analysis based on successful and not-so-successful innovations can validate, complement or contradict the findings with successful innovations only. In contrast to the typical description of the industry having experienced major changes in almost every ten years (American Tennis Industry Federation 1991), this research has documented that the tennis racket industry has evolved through not only ex post successful innovations but also several not-so-successful innovations.

In addition, this study illustrates that the success of a particular racket design is ex ante not clear at all. Anecdotal evidence suggests that ex post successful innovations initially suffer from severe criticism and outright rejection by numerous incumbents in the industry.

Quantitative information also complements anecdotal evidence: some of the ex post not-so

environment, and the former is the object of the evolutionary forces of the latter. However, as organisms determine which parts of the environment are relevant for their survival and constantly attempt to alter their environment in their favor, he argued that "the actual process of evolution seems best captured by the process of construction” (Lewontin 2000: 48, italics original). 
successful innovations received very high scores in racket performance tests. By comparing successful and not-so-successful innovations, we showed that quality of innovation, although ambiguous, cannot fully explain what happened in this particular industry.

This study has some limitations. First, since customer acceptance remains unobserved in this research, we remain agnostic about the mediation that could be revealed through sales volumes and growth in volumes. The variable of interest here was the number of new rackets launched by the innovating firm's competitors. As we indicated in exhibit A, a new racket design introduction occasions innovative replication. We cannot separate learning that involves competitors' learning from each other as opposed to their learning from consumers - whether as endorsers or as consumers at large - since sales data are lacking. Nor can we ascertain the factors that account for a pioneering or innovating firm to incur the introduction of the very first model appropriate instrumental variable to predict such action is also beyond the reach of these researchers. In short, we cannot link new product introduction to sales. While the data set employed here has unusual advantages for documenting the firm-customer interplay, like always, we also suffer from data limitations that preclude more comprehensive conclusions regarding diffusion and industry level learning.

Second, since the racket performance test of World Tennis only covers the period from the early 1980s to the early 1990s, some of the interesting innovations have been right censored. For example, the Kinetic Technology by Pro Kennex which received the product of the year award from Popular Science was not included in the analysis due to missing data. Also due the lack of sales data, we could not extend the research to track the rent-adjusted cost of such product promotion; it is only suggested that professional endorsement increases the chance of racket design replication.

Third, some might argue that the sporting goods industries, the tennis racket industry in particular, have some peculiarities that are at variance with those of others sectors in that the influence of well-known professional players is unusually high. Tennis players in the limelight of 
major competitive events are also much smaller in numbers when competing for exposure, compared to large numbers of soccer, basketball or baseball players. However, recent studies demonstrate that the endorsement by and the relationship with prominent firms in the industry have significant effects on the fate of patents and projects (e.g., Podolny and Stuart 1995). Podolny (2005) also points to the phenomenon of status leakage which in our study could be advanced as being diffusion relevant, although we included two status systems - producers and top professional players. Much of the research on "systems" to date has presumed their identity to be insular and self-sustaining.

The research reported here also has ramifications for the distinction between status (Podolny 2005), brand (Hoch 2004) and reputation (e.g., Kreps 1990). The relationship among these concepts remains elusive, particularly in the context of firms and their external constituents such as suppliers and customers. The earlier mentioned concept of open innovation and the full integration of the customer into the product development process need to move to the center stage in innovation research. Even a phenomenon like endorsement is too limited to capture the proactive engagement of consumers as observed in domains such as Linux communities. Earlier we cited some endorsing stars who might be embedded in their network of peer-players, but acted rather opportunistically vis-à-vis racket manufacturers, suggesting the importance of arms-length relationships in which reputations become built and dismantled (by analogy, compare Uzzi (1997) who contrasted atomistic vs. embedded relationships in his study of apparel manufacturers). In the present context, information on the population of "tennis pros," their tennis clinics and other local networks with their role as opinion leaders could be collected so that grass root level data on innovation diffusion can extend the current line of inquiry, and be characterized as arms-length or embedded. Furthermore, sales volume data could track the rate of diffusion and reveal the extent to which mediation (type, density, latency) between firms and consumers results in customer acceptance. Unfortunately as indicated earlier, sales by racket type or product was not yet 
obtainable; these became only accessible as of 1991 and hardly overlapped with the window of our study.

Finally, industries undergoing discontinuous innovations offer ample opportunity for investigating strategic renewal. In this study, we could only present information of three cursory firm attributes, but we have to remain agnostic on the adaptive challenges that manufacturers encounter when they face discontinuities in the market place. While such discontinuities are associated with massive rates of failure, we could not document such adjustment difficulties among firms suffering from obsolete knowledge heritage. We could merely flag firms that compete as incumbents versus start-ups and ought to examine why many innovations originate from outside the set of incumbents, suggesting that they lack the dynamic capabilities to pioneer new products. Diversified firms might exploit economies of scope such that knowledge from one line of business can be replicated elsewhere. Specialized firms might be strongly entrenched. In the present study, information on more specific firm attributes is absent.

A firm needs to leverage its status or reputation in order to succeed as innovator and to coalesce with consumers in achieving the introduction and market acceptance of its innovations. It might leverage its branding as the industry migrates into a new phase as illustrated in the wellknown cases of Swiss watch and global photo-equipment industries which moved from mechanical to electronic architectures. The research reported here opens up new lines of inquiry on the relationship between firms, their consumers and the intricate relationships between producers and consumers in realizing an innovation's potential, supplied by the former and acquired by the latter. Ultimately, the research on innovation ought to frame the firm - consumer interface as a recursive relationship in which both are engaged in the social construction of innovation. The tennis racket is an artifact that is embedded in a body of beliefs and practices, which comprise producers and consumers. The arrival of discontinuous technologies might disrupt such relationships but more appropriately, such arrival should be conceived as a transient event in ongoing interactions in which innovation is collectively constructed and modified. 
Consumers integrate the technology into their activity and accumulate experience in its use as the technology becomes more widely diffused. Producers also travel along a diffusion curve, locking them into established market equilibria, until a discontinuous technology triggers the emergence of a new platform of practices and institutions. What has been left out of such framing is the interplay between producers and consumers, as if they represent separate and non-overlapping groups, status systems, or "institutional fields.” Often the consumer is a passive bystander as producers move through cycles of reorientations and adjustments. We should view both as participants on a "stage” that often is labeled as market or sector, but is typically truncated towards a supply-side phenomenon.

Whether innovations are incremental or discontinuous depends critically on the social construction that comprises a product or service but is much more comprehensive in its totality than the mere product attributes that we identified to map the events in the window of study. While the racket is tangible and visible, its evolving properties are merely one of the many guideposts (Sahal 1989) that inform us about stages in technological evolution. The process of refashioning firm - consumer relationships around an artifact in the market remains to be examined, but the findings presented here invite new lines of investigation on customer empowerment, institutionalization, networking, and open innovation. 


\section{References}

Adner. R. 2002. When are technologies disruptive? A demand-based view of the emergence of competition. Strategic Management J. 23 667-688.

Afuah, A., N. Bahram. 1995. The hypercube of innovation. Res. Policy 24 51-76.

Agarwal, R., B. Bayus. 2002. The market evolution and sales takeoff of product innovations. Management Sci. 48 1024-1041.

Aiken, L., S. West. 1991. Multiple Regression: Testing and Interpreting Interactions. Sage Publications, Thousand Oaks, CA.

Allison, P. 1999. Logistic Regression Using the SAS System: Theory and Application. SAS Institute, Inc., Cary, NC.

Amendola, M., S. Bruno. 1990. The behavior of the innovative firm: Relations to the environment. Res. Policy 19 419-433.

American Tennis Industry Federation. 1991. Tennis racquets: 30 years of change. North Palm Beach, FL.

Anderson, P., M. Tushman. 1990. Technological discontinuities and dominant designs: A cyclical model of technological change. Admin. Sci. Quart. 35 604-633.

Argote, L., S. Beckman, D. Epple. 1990. The persistence of learning in industrial settings. Management Sci. 36(1) 140-154.

Arthur, B. 1989. Competing technologies, increasing returns, and lock-in by historical events. Econom. J. 99 116-131.

Ashley, S. 1993. High-tech rackets hold court. Mechanical Engineering. August, 80-81.

Aversi, R., G. Dosi, G. Fagiolo, M. Meacci, and C. Olivetti. 1999. Demand dynamics with socially evolving preferences. Indust. Corporate Change 8 353-408.

Bass, F. M. 1969. A new growth model for consumer durables. Management Sci. 15 215-227.

Baum, P. J., 1998. Go-faster strips, stripes, riblets, etc.: Speedskating drag reduction and the 'Lost Dutchman Olympic Gold Mine'. http://home1.gte.net/pjbemail/RibletFlow.html

Bothner, M. 2003. Competition and social influence: The diffusion of the sixth-generation processor in the global computer industry. Amer. J .Sociology 108 1175-1210.

Boyd T.C., and Mason, C.H. 1999. The link between attractiveness of "extrabrand" attributes and the adoption of innovations. J. Acad. Marketing Sci. 27 306-319

Brody, H. 1979. Physics of the tennis racket. Amer. J. Physics 47 482-487.

Brody, H. 1981. Physics of the tennis racket II: The "sweet spot". Amer. J. Physics $49816-$ 819.

Brody, H. 1997. Physics of the tennis racket III: The ball-racket interaction. Amer. J. Physics 65 981-987. 
Burt, R.S. 1987. Social contagion and innovation: Cohesion versus structural equivalence. Amer. J. Sociology 92 1287-1335.

Cameron, A. C., P. Trivedi. 1998. Regression analysis of count data. Cambridge University Press, New York, NY.

Carpenter, G., R. Glazer, K. Nakamoto. 2000. Market-driving strategies: Toward a new concept of competitive advantage. D. Iacobucci, L. Krishnamurthi, eds. Kellogg on Marketing, Wiley \& Sons, New York, NY, 103-129.

Carpenter, G., K. Nakamoto. 1989. Consumer preference formation and pioneering advantage. J. Marketing Res. 26 285-298.

Chandy, R. K, G. Tellis, D. MacInnis, and P. Thaivanich. 2001. When to say when: Advertising appeals in evolving markets. J. Marketing Res. 38 399-414.

Chesbrough, H. 2003. Open Innovation. Harvard Business School Press, Boston, MA.

Christensen, C. 1997. The Innovator's Dilemma: When New Technologies Cause Great Firms to Fail. Harvard Business School Press, Boston, MA.

Collins, B., Z. Hollander. 1994. Bud Collins’ modern encyclopedia of tennis. Gale Research Inc,. Detroit, MI.

Cowan, R., W. Cowan, P. Swann. 1997. A model of demand with interactions among consumers. Internat. J. Indust. Organ. 15 711-732.

Cusumano, M., Y. Mylonadis, R. Rosenbloom. 1992. Strategic maneuvering and mass-market dynamics: The triumph of VHS over Beta. Bus. History Rev. 66 51-94.

Cyert, R., J. March. 1963. A Behavioral Theory of the Firm. Prentice-Hall, Englewood Cliffs, NJ.

Dahlin, K., D. Behrens. 2005. When is an invention really radical? Defining and measuring technological radicalness. Res. Policy 34 717-737.

David, P. 1985. Clio and the economics of QWERTY. Amer. Econ. Rev. 75 332-337.

Davis, G. F. 1991. Agents without principles. The spread of the poison pill through the intercorporate network. . Admin. Sci. Quart. 36 583-613

DiMaggio, P., W. Powell. 1983. The iron cage revisited: Institutional isomorphism and collective rationality in organizational fields. Amer. Sociological Rev. 48 147-160.

Doherty, D. 1997. An exo-llent idea? Tennis, March, 121.

Felcyn, K. 1996. Tennis: Should you buy a long racket? Business Week, July 15, 84.

Fiott, S. 1978. Whys and wherefores of the racket revolution. World Tennis. July, 93-100.

Franke, N., S. Shah. 2003. How communities support innovative activities: An exploration of assistance and sharing among end-users. Res. Policy 32 1199-1215. 
Frenzen, J., P. Hirsch, P. Zerrillo. 1994. Consumption, preferences, and changing lifestyles. N. Smelser, R. Swedberg, eds. Handbook of Economic Sociology, Russell Sage Foundation, Princeton, NJ, 403-425.

Galbraith, J. K. 1958. The Affluent Society. Houghton Mifflin, Boston, MA.

Ganesh, J., V. Kumar. 1996. Capturing the cross-national learning effect: an analysis of an industrial technology diffusion. J. Acad. Marketing Sci. 24 328-337.

Gavetti, G., D.A Levinthal. 2000. Looking Forward and Looking Backward: Cognitive and Experiential Search. Admin. Sci. Quart. 45 113-137.

Glynn, S. 2002. Constructing a selection environment: Competing expectations for CFC alternatives. Res. Policy 31 935-946.

Golder, P., G. Tellis. 2004. Growing, growing, gone: Cascades, diffusion and turning points in the product life cycle. Marketing Sci. 23 207-218.

Ha, Y.-W., S. Hoch. 1989. Ambiguity, processing strategy, and advertising-evidence interaction. J. Consumer Res. 16 354-360.

Hannan, M., J. Freeman. 1977. The population economy of organizations. Amer. J. Sociology 82 929-964.

Heilman, C., D. Bowman, G. Wright. 2000. The evolution of brand preferences and choice behaviors of consumer new to a market. J. Marketing Res. 37 139-155.

Hoch, S. 1984. Hypothesis testing and consumer behavior: 'If it works, don't mess with it.' T. Kinner, ed. Advances in Consumer Research 11 478-483.

Hoch, S. 2002. Product experience is seductive. J. Consumer Res. 29 448-454.

Hoch, S., Y.-W. Ha. 1986. Consumer learning: Advertising and the ambiguity of product experience. J. Consumer Res. 13 221-233.

Hoeffler, S., D. Ariely. 1999. Constructing stable preferences: A look into dimensions of experience and their impact on preference stability. J. Consumer Psych. 8 113-139.

Huston, L., N. Sakkab. 2006. Connect and develop: Inside Procter and Gamble’s new model of innovation. Harvard Bus. Rev. 84 1-12.

Kahle, L., P. Homer. 1985. Physical attractiveness of the celebrity endorse: A social adaptation perspective. J. Consumer Res. 11 954-961.

Kahneman, D., P. Slovic, A. Tversky. 1982. Judgment under Uncertainty: Heuristics and Biases. Cambridge University Press, New York, NY.

Katz, M., C. Shapiro. 1985. Network externalities, competition, and compatibility. Amer. Econom. Rev. 75(3) 424-440.

Kempf, D., R. Smith. 1998. Consumer processing of product trial and the influence of prior advertising: A structural modeling approach. J. Marketing Res. 35 325-338. 
Kleinbaum, D., L. Kupper, K. Muller. 1988. Applied Regression Analysis and Other Multivariable Methods. Duxburry Press, Belmont, CA.

Klepper, S. 1996. Entry, exit, growth, and innovation over the product life cycle. Amer. Econom. Rev. 86(3) 562-583.

Kreps, D. 1990. Corporate Culture and Economic Theory. In Alt, J., K. Shepsle (eds)

Perspectives on Positive Political Economy. Cambridge University Press, New York, NY, 90143.

Le Marche, R. 1986. How the Prince patent has changed the game. Tennis 21(April) 106-116.

Lee, K., J. M. Pennings. 2002. Mimicry and the market. Acad. Management J. 45 144-162.

Levine, S. S., J. M. Pennings. 2007. Janus, laymen and Status: Some novel considerations in product architecture. Paper presented at Annual Meetings of Academy of Management, Philadelphia.

Levinthal, D.A. 1992. Surviving Schumpeterian environments: An evolutionary perspective.

Indust. Corporate Change 1 427-443.

Lewontin, R. 2000. The Triple Helix: Gene, Organism, and Environment. Harvard University Press, Cambridge, MA.

McKelvey, M. 1998. Evolutionary innovation: Learning, entrepreneurship and the dynamics of the firm. J. Evol. Econom. 8 157-175.

Malerba, F. 2006. Innovation and the evolution of industries. J. Evol. Econom. 16 3-23.

March, J.G. 1978. Bounded rationality, ambiguity, and the engineering of choice. Bell J. Econom. 9(2) 587-598.

March, J.G. 1988. The technology of foolishness. In Decisions and Organizations, Blackwell, Cambridge, MA, 253-265.

Meadow, B. 1983. Swinging for dollars. World Tennis. February 43-48.

Metcalfe, S. 2001. Consumption, preferences, and the evolutionary agenda. J. Evol. Econom. 11 37-58.

Noble, D. 1984. Forces of Production: A Social History of Industrial Automation. Knopf, New York, NY.

Nonaka, I. 1994. A dynamic theory of organizational knowledge creation. Organ. Sci. 5 14-37.

Ohanian, R. 1991. The impact of celebrity spokespersons' perceived image on consumers' intention to purchase. J. Advertising Res. X 46-54.

Patterson, B. 1999. Personal communication. Director of the Tennis Industry Association.

Payne, J., J. Bettman, E. Johnson. 1992. Behavioral decision research: A constructive processing perspective. Annu. Rev. Sociology 43 87-131.

Penrose, E. 1952. Biological analogies in the theory of the firm. Amer. Econom. Rev. 42 804819. 
Piller, F. 2001. Mass customization and personalization in electronic business. Wirtschaftlichen Stud. 30 88-96.

Pinch, T., W. Bijker. 1987. The social construction of facts and artifacts: Or how the sociology of science and the sociology of technology might benefit each other. In Bijker, W., T. Hughes, T. Pinch, eds. The Social Construction of Technological Systems, MIT Press, Cambridge, MA, 1750 .

Podolny, J. 2005. Status Signals. Princeton University Press, Princeton, NJ.

Podolny, J., T. Stuart. 1995. A role-based ecology of technical change. Amer. J. Sociology 100 1224-1260.

Rogers, E. 1995. Diffusion of Innovations. 4th ed. Free Press, New York, NY.

Rosa, J., J. Porac, J. Runsel, and M.S.Saxon, 1999. Socio-cognitive dynamics in a product market. J. Marketing 63 64-77.

Rosenkopf, L., M. Tushman. 1998. The co-evolution of community networks and technology: Lessons from the flight simulation industry. Indust. Corporate Change 7 311-346.

Sahal, D.1981. Patterns of Technological Innovation. Addison Wesley, Reading, MA.

Schumpeter, J. A. 1934. The Theory of Economic Development. Harvard University Press, Cambridge, MA.

Schumpeter, J. A. 1939. Business Cycles: A Theoretical, Historical, and Statistical Analysis of the Capitalist Process. McGraw-Hill Book Company, New York, NY.

Stoneman, P., N. Ireland. 1983. The role of supply factors in the diffusion of new process technologies. Econ. J. Supplement(March) 65-77.

Tripsas, M. 1997. Unraveling the process of creative destruction: Complementary assets and incumbent survival in the typesetter industry. Strategic Management J. 18 (Summer special issue) $119-142$.

Tushman, M., L. Rosenkopf. 1992. Organizational determinants of technological change: Towards a sociology of technological evolution. B. Staw, L. Cummings. eds. Research in Organizational Behavior, 14 311-347.

Uzzi, B 1997. Social structure and interfirm networks: the paradox of embeddedness. Admin. Sci. Quart. 42(1) 35-67.

Van de Ven, A., R. Garud. 1994. The coevolution of technical and institutional events in the development of an innovation. J.A.C. Baum, J.V. Singh, eds. Evolutionary Dynamics of Organizations, Oxford University Press, New York, NY, 425-443.

Van den Bulte, C., G. Lilien. 2001. Medical Innovation Revisited: Social Contagion versus Marketing Effort. Amer. J. Sociology 1061409 - 1435.

Veryzer, R. 1998. Key factors affecting customer evaluation of discontinuous new products. J. Product Innovation Management. 15 136-150. 
Von Hippel, E. 1986. Lead users: A source of novel product concepts. Management Sci. 32 91805.,

Windrum, P., C. Birchenhall. 1998. Is product life cycle theory a special case? Dominant designs and the emergence of market niches through coevolutionary-learning. Structural Change and Econom. Dynamics $9109-134$.

Witt, U. 2001. Learning to consume - A theory of wants and the growth of demand, J. Evol. Econom. 11 23-36.

Wright, T. P. 1936. Factors affecting the costs of airplanes. J. Aeronautical Sci. 3 (4) 122-128. 
[Exhibit A] Graphic Representation of Theory and Hypotheses, Observed Relationships
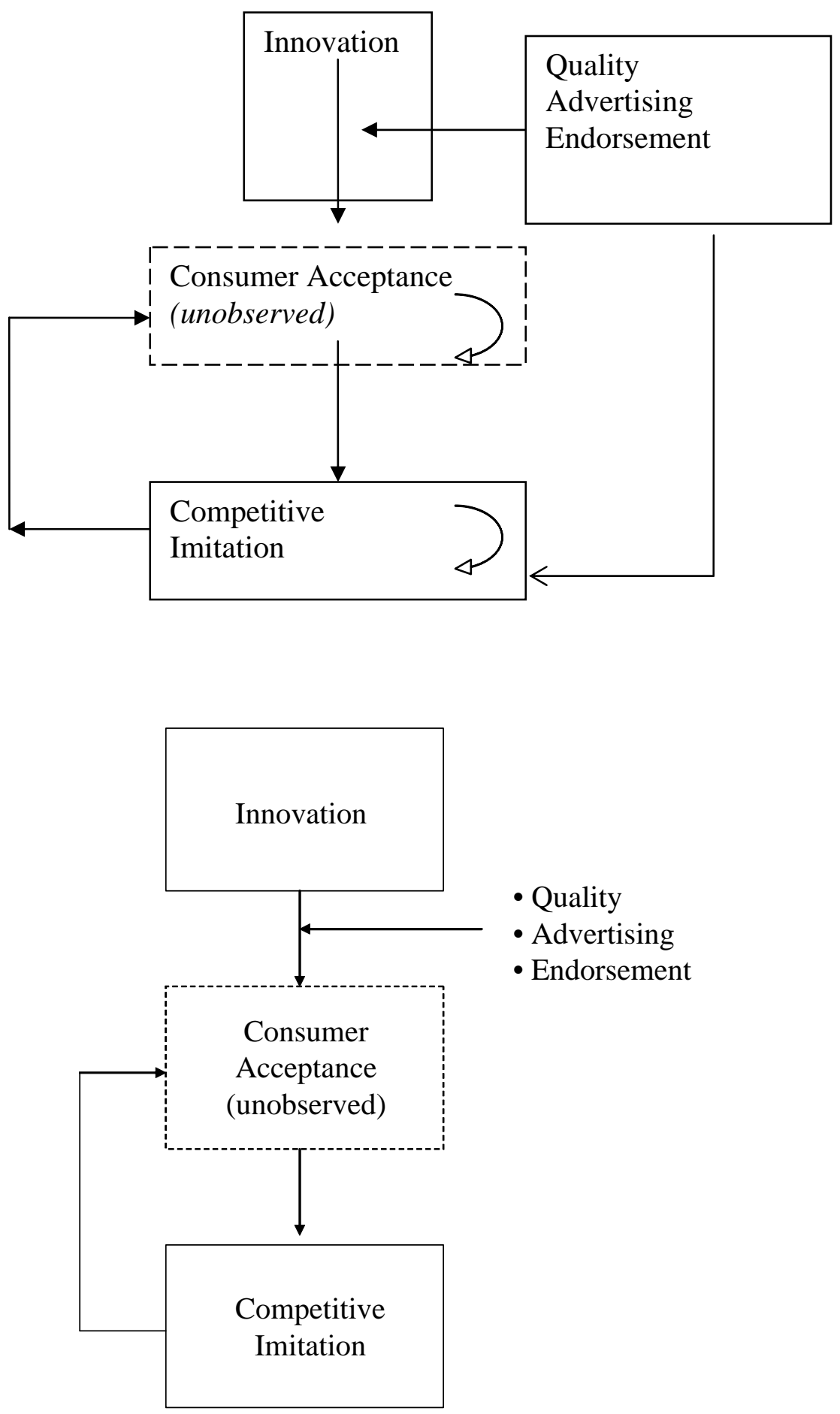


\section{[ Table 1 ] Discontinuous Racket Designs Included in the Empirical Analysis}

\begin{tabular}{|c|c|c|c|}
\hline Design & Year & Innovator & Description \\
\hline Oversize & 1976 & Prince & $\begin{array}{l}\text { - Enlargement of the sweet spot } \\
\text { - } 110 \text { square inches of the racket head (traditional rackets had the } \\
\text { face of } 70 \text { square inches) }\end{array}$ \\
\hline $\begin{array}{l}\text { Adjustable String } \\
\text { Tension }\end{array}$ & 1976 & Fischer & - Equipped with tension adjusting device \\
\hline Longbody & 1979 & Head & - Longer than the traditional 27 inch racket \\
\hline $\begin{array}{l}\text { Perimeter Weighting } \\
\text { System }\end{array}$ & 1981 & Wilson & $\begin{array}{l}\text { - Put more weights at } 3 \text { o'clock and } 9 \text { o'clock positions on the frame } \\
\text { to increase the stability of the racket }\end{array}$ \\
\hline Ergonomic Design & 1983 & Sentra & $\begin{array}{l}\text { - } 13 \text { degree bent grip for lessening stress on the muschles of the arm } \\
\text { and wrist when players hit the ball with the racket }\end{array}$ \\
\hline Convex Throat & 1984 & Chris & - Wide throat design for increased stability \\
\hline Three String Pattern & 1986 & Mad Raq & - Strings woven in three directions for increased stiffness \\
\hline Widebody & 1987 & Wilson & $\begin{array}{l}\text { - Different frame width throughout the frame } \\
\text { - Thin at the tip and bottom of the frame, thick in the middle for } \\
\text { increased stiffness }\end{array}$ \\
\hline
\end{tabular}


[ Table 2 ] Descriptive Statistics and Correlation Matrix of the Variables

\begin{tabular}{|c|c|c|c|c|c|c|c|c|c|c|c|c|c|c|}
\hline Variable & Mean & S.D. & 1 & 2 & 3 & 4 & 5 & 6 & 7 & 8 & 9 & 10 & 11 & 12 \\
\hline $\begin{array}{l}\text { 1. Number of New Rackets with Focal } \\
\text { Innovation }\end{array}$ & 4.37 & 8.97 & & & & & & & & & & & & \\
\hline 2. Tennis Playing Population (millions) & 18.89 & 2.78 & -0.02 & & & & & & & & & & & \\
\hline 3. Number of Firms & 33.70 & 4.41 & 0.01 & $0.86^{* * *}$ & & & & & & & & & & \\
\hline 4. Number of Rackets & 203.91 & 52.68 & 0.07 & $-0.53^{* * *}$ & $0.78^{* * *}$ & & & & & & & & & \\
\hline 5. New Entrant (1=Yes; $0=$ No) & 0.39 & 0.49 & $0.36^{* *}$ & -0.02 & 0.01 & -0.01 & & & & & & & & \\
\hline 6. Diversified ( $1=$ Yes; $0=\mathrm{No})$ & 0.61 & 0.49 & $0.39^{* *}$ & $0.02^{*}$ & -0.01 & 0.01 & $-0.41^{* *}$ & & & & & & & \\
\hline 7. U.S. Firm (1=Yes; $0=$ No) & 0.75 & 0.43 & $0.28^{* *}$ & 0.02 & -0.02 & -0.01 & $0.45^{* * *}$ & 0.22 & & & & & & \\
\hline 8. Log (Age of Innovation) & 1.74 & 0.83 & $0.34^{*}$ & $0.23^{\dagger}$ & -0.21 & -0.13 & -0.17 & $0.55^{* * *}$ & -0.09 & & & & & \\
\hline 9. Innovation Quality & 0.27 & 0.75 & $0.33^{*}$ & 0.16 & -0.16 & -0.11 & -0.20 & $0.25^{\dagger}$ & $0.34^{* *}$ & 0.31 & & & & \\
\hline 10. Advertising by All Firms & -0.11 & 6.88 & $0.83^{* * *}$ & 0.06 & -0.05 & -0.04 & $0.38^{* *}$ & $0.41^{* *}$ & $0.30^{*}$ & $0.26^{\dagger}$ & $0.42^{* *}$ & & & \\
\hline 11. Advertising by Innovator & -0.01 & 1.75 & $0.71^{* * *}$ & 0.04 & -0.10 & -0.13 & $0.32^{*}$ & $0.35^{* *}$ & $0.27^{*}$ & $0.26^{*}$ & $0.36^{* *}$ & $0.81^{* * *}$ & & \\
\hline 12. Advertising by Imitator & -0.10 & 5.54 & $0.81^{* * *}$ & 0.07 & -0.03 & -0.01 & $0.37^{* *}$ & $0.41^{*}$ & $0.29^{*}$ & $0.23 \dagger$ & $0.41^{* *}$ & $0.98^{* * *}$ & $0.69^{* * *}$ & \\
\hline 13. Professional Endorsement & 0.10 & 2.32 & $0.81^{* * *}$ & 0.11 & -0.09 & -0.04 & $0.27^{*}$ & $0.47^{* * *}$ & $0.34^{*}$ & $0.42^{* *}$ & $0.45^{* * *}$ & $0.88^{* * *}$ & $0.71^{* * *}$ & $0.87^{* * *}$ \\
\hline
\end{tabular}

${ }^{\dagger} \mathrm{p}<0.10 ;{ }^{*} \mathrm{p}<0.05 ;{ }^{* *} \mathrm{p}<0.01 ;{ }^{* * *} \mathrm{p}<0.001$ 


\section{[ Table 3 ] Negative Binomial Regression on}

\section{Discontinuous Racket Design Replication by Competitors}

\begin{tabular}{|c|c|c|c|c|c|c|c|c|}
\hline Variable & Model 1 & Model 2 & Model 3 & Model 4 & Model 5 & Model 6 & Model 7 & Model 8 \\
\hline Intercept & $\begin{array}{l}-50.183^{*} \\
(17.257)\end{array}$ & $\begin{array}{l}-48.810^{*} \\
(21.352)\end{array}$ & $\begin{array}{l}-33.550^{*} \\
(17.112)\end{array}$ & $\begin{array}{l}-47.360^{*} \\
(21.510)\end{array}$ & $\begin{array}{l}-36.397^{*} \\
(18.206)\end{array}$ & $\begin{array}{l}-38.721^{\dagger} \\
(21.192)\end{array}$ & $\begin{array}{l}-29.423 \\
(21.844)\end{array}$ & $\begin{array}{l}-32.758^{\dagger} \\
(19.257)\end{array}$ \\
\hline \multicolumn{9}{|l|}{ Environment Characteristics } \\
\hline Tennis Playing Population & $\begin{array}{l}-0.061 \\
(0.086)\end{array}$ & $\begin{array}{l}-0.060 \\
(0.087)\end{array}$ & $\begin{array}{l}-0.001 \\
(0.090)\end{array}$ & $\begin{array}{c}0.064 \\
(0.104)\end{array}$ & $\begin{array}{c}0.052 \\
(0.093)\end{array}$ & $\begin{array}{l}-0.001 \\
(0.090)\end{array}$ & $\begin{array}{c}0.101 \\
(0.105)\end{array}$ & $\begin{array}{c}0.033 \\
(0.091)\end{array}$ \\
\hline Number of Firms & $\begin{array}{r}3.087^{*} \\
(1.402)\end{array}$ & $\begin{array}{r}2.969^{*} \\
(1.358)\end{array}$ & $\begin{array}{l}1.828^{\dagger} \\
(1.065)\end{array}$ & $\begin{array}{r}2.532^{\dagger} \\
(1.312)\end{array}$ & $\begin{array}{r}1.949^{\dagger} \\
(1.128)\end{array}$ & $\begin{array}{c}2.175 \\
(1.364)\end{array}$ & $\begin{array}{l}1.298 \\
(1.368)\end{array}$ & $\begin{array}{c}1.826 \\
(1.232)\end{array}$ \\
\hline Number of Firms ${ }^{2}$ & $\begin{array}{l}-0.046^{*} \\
(0.020)\end{array}$ & $\begin{array}{l}-0.044^{*} \\
(0.020)\end{array}$ & $\begin{array}{l}-0.026^{\dagger} \\
(0.015)\end{array}$ & $\begin{array}{l}-0.036^{\dagger} \\
(0.019)\end{array}$ & $\begin{array}{l}-0.027^{\dagger} \\
(0.016)\end{array}$ & $\begin{array}{l}-0.031 \\
(0.020)\end{array}$ & $\begin{array}{l}-0.017 \\
(0.020)\end{array}$ & $\begin{array}{l}-0.026 \\
(0.018)\end{array}$ \\
\hline Number of Rackets & $\begin{array}{l}-0.031 \\
(0.023)\end{array}$ & $\begin{array}{l}-0.026 \\
(0.025)\end{array}$ & $\begin{array}{l}-0.017 \\
(0.020)\end{array}$ & $\begin{array}{l}-0.014 \\
(0.025)\end{array}$ & $\begin{array}{l}-0.024 \\
(0.021)\end{array}$ & $\begin{array}{l}-0.020 \\
(0.024)\end{array}$ & $\begin{array}{l}-0.006 \\
(0.024)\end{array}$ & $\begin{array}{l}-0.018 \\
(0.022)\end{array}$ \\
\hline Number of Rackets ${ }^{2}$ & $\begin{array}{l}-0.000 \\
(0.000)\end{array}$ & $\begin{array}{c}0.000 \\
(0.000)\end{array}$ & $\begin{array}{l}0.000 \\
(0.000)\end{array}$ & $\begin{array}{c}0.000 \\
(0.000)\end{array}$ & $\begin{array}{c}0.000 \\
(0.000)\end{array}$ & $\begin{array}{c}0.000 \\
(0.000)\end{array}$ & $\begin{array}{c}0.000 \\
(0.000)\end{array}$ & $\begin{array}{c}0.000 \\
(0.000)\end{array}$ \\
\hline \multicolumn{9}{|l|}{ Innovator Characteristics } \\
\hline $\begin{array}{l}\text { New Entrant } \\
(1=\text { yes; } 0=\text { no })\end{array}$ & $\begin{array}{l}-0.531 \\
(1.105)\end{array}$ & $\begin{array}{l}-0.499 \\
(1.104)\end{array}$ & $\begin{array}{l}1.177^{*} \\
(0.462)\end{array}$ & $\begin{array}{c}1.227 \\
(1.051)\end{array}$ & $\begin{array}{l}1.609^{* * *} \\
(0.165)\end{array}$ & $\begin{array}{c}0.710 \\
(1.159)\end{array}$ & $\begin{array}{l}2.531^{*} \\
(1.210)\end{array}$ & $\begin{array}{c}1.340 \\
(1.152)\end{array}$ \\
\hline $\begin{array}{l}\text { Diversified } \\
\text { (1=yes; } 0=\text { no })\end{array}$ & $\begin{array}{l}1.906 \\
(1.415)\end{array}$ & $\begin{array}{l}1.914 \\
(1.428)\end{array}$ & $\begin{array}{l}3.632^{* * *} \\
(1.021)\end{array}$ & $\begin{array}{c}3.908^{*} \\
(1.650)\end{array}$ & $\begin{array}{l}4.572^{* * *} \\
(1.282)\end{array}$ & $\begin{array}{r}3.112^{*} \\
(1.531)\end{array}$ & $\begin{array}{l}5.156^{* *} \\
(1.804)\end{array}$ & $\begin{array}{l}4.333^{* *} \\
(1.627)\end{array}$ \\
\hline $\begin{array}{l}\text { U.S. Firm } \\
(1=\text { yes; } 0=\text { no })\end{array}$ & $\begin{array}{r}2.060^{\dagger} \\
(1.086)\end{array}$ & $\begin{array}{r}2.094^{\dagger} \\
(1.089)\end{array}$ & $\begin{array}{l}0.828 \\
(1.113)\end{array}$ & $\begin{array}{l}-0.029 \\
(1.537)\end{array}$ & $\begin{array}{l}-0.478 \\
(1.429)\end{array}$ & $\begin{array}{c}1.014 \\
(1.168)\end{array}$ & $\begin{array}{l}-0.907 \\
(1.642)\end{array}$ & $\begin{array}{l}-0.805 \\
(1.488)\end{array}$ \\
\hline \multicolumn{9}{|l|}{ Innovation Characteristics } \\
\hline Log (Age) & $\begin{array}{c}0.352 \\
(0.322)\end{array}$ & $\begin{array}{c}0.378 \\
(0.328)\end{array}$ & $\begin{array}{l}-0.358 \\
(0.308)\end{array}$ & $\begin{array}{l}0.077 \\
(0.444)\end{array}$ & $\begin{array}{l}-0.599^{\dagger} \\
(0.318)\end{array}$ & $\begin{array}{l}-0.234 \\
(0.414)\end{array}$ & $\begin{array}{l}-0.575 \\
(0.534)\end{array}$ & $\begin{array}{l}-0.061 \\
(0.526)\end{array}$ \\
\hline Quality & $\begin{array}{l}-0.179 \\
(0.369)\end{array}$ & $\begin{array}{l}-0.192 \\
(0.372)\end{array}$ & $\begin{array}{l}0.004 \\
(0.369)\end{array}$ & $\begin{array}{c}0.842 \\
(0.516)\end{array}$ & $\begin{array}{c}0.763 \\
(0.482)\end{array}$ & $\begin{array}{l}-0.043 \\
(0.384)\end{array}$ & $\begin{array}{r}0.895^{\dagger} \\
(0.537)\end{array}$ & $\begin{array}{c}0.755 \\
(0.459)\end{array}$ \\
\hline Advertising (Overall) & $\begin{array}{c}0.169^{*} \\
(0.068)\end{array}$ & & & & & & & \\
\hline Advertising by Innovator & & $\begin{array}{c}0.117 \\
(0.120)\end{array}$ & & $\begin{array}{l}-0.228 \\
(0.239)\end{array}$ & & $\begin{array}{c}0.018 \\
(0.125)\end{array}$ & $\begin{array}{l}-0.282 \\
(0.239)\end{array}$ & $\begin{array}{l}-0.270 \\
(0.227)\end{array}$ \\
\hline Advertising by Imitator & & $\begin{array}{c}0.178^{*} \\
(0.076)\end{array}$ & & $\begin{array}{c}0.147 \\
(0.082)\end{array}$ & & $\begin{array}{c}0.041 \\
(0.090)\end{array}$ & $\begin{array}{l}-0.014 \\
(0.110)\end{array}$ & $\begin{array}{c}0.068 \\
(0.101)\end{array}$ \\
\hline Professional Endorsement & & & $\begin{array}{l}0.396^{* *} \\
(0.133)\end{array}$ & & $\begin{array}{c}0.363^{*} \\
(0.158)\end{array}$ & $\begin{array}{c}0.354^{*} \\
(0.163)\end{array}$ & $\begin{array}{r}0.446^{\dagger} \\
(0.232)\end{array}$ & $\begin{array}{r}0.520^{*} \\
(0.206)\end{array}$ \\
\hline \multicolumn{9}{|l|}{ Interaction } \\
\hline $\begin{array}{l}\text { Log (Age) x } \\
\text { Quality }\end{array}$ & & & & $\begin{array}{c}0.849^{* *} \\
(0.263)\end{array}$ & $\begin{array}{l}0.731^{* *} \\
(0.235)\end{array}$ & & $\begin{array}{l}0.843^{* *} \\
(0.266)\end{array}$ & $\begin{array}{c}0.698^{* *} \\
(0.250)\end{array}$ \\
\hline $\begin{array}{l}\text { Log (Age) } \mathrm{x} \\
\text { Advertising by Innovator }\end{array}$ & & & & $\begin{array}{c}0.354 \\
(0.321)\end{array}$ & & & $\begin{array}{c}0.320 \\
(0.321)\end{array}$ & $\begin{array}{r}1.181^{*} \\
(0.528)\end{array}$ \\
\hline $\begin{array}{l}\text { Log (Age) } x \\
\text { Advertising by Imitator }\end{array}$ & & & & $\begin{array}{l}-0.134 \\
(0.089)\end{array}$ & & & $\begin{array}{l}-0.102 \\
(0.094)\end{array}$ & $\begin{array}{c}0.086 \\
(0.126)\end{array}$ \\
\hline $\begin{array}{l}\text { Log (Age) } \mathrm{x} \\
\text { Professional Endorsement }\end{array}$ & & & & & $\begin{array}{l}-0.190 \\
(0.153)\end{array}$ & & $\begin{array}{l}-0.203 \\
(0.254)\end{array}$ & $\begin{array}{l}-0.424^{\dagger} \\
(0.224)\end{array}$ \\
\hline $\begin{array}{l}\text { Professional Endorsement x } \\
\text { Advertising by Innovator }\end{array}$ & & & & & & & & $\begin{array}{l}-0.140^{*} \\
(0.061)\end{array}$ \\
\hline $\begin{array}{l}\text { Professional Endorsement x } \\
\text { Advertising by Imitator }\end{array}$ & & & & & & & & $\begin{array}{l}-0.031^{*} \\
(0.016)\end{array}$ \\
\hline Log Likelihood & 471.46 & 471.45 & 473.79 & 478.42 & 479.38 & 473.89 & 480.55 & 485.43 \\
\hline Degrees of Freedom & 55 & 54 & 55 & 51 & 53 & 53 & 49 & 47 \\
\hline
\end{tabular}

${ }^{\dagger} \mathrm{p}<0.1 ;{ }^{*} \mathrm{p}<0.05 ;{ }^{* *} \mathrm{p}<0.01 ;{ }^{* * *} \mathrm{p}<0.001$ 